\title{
The Effect of Insulin on Renal Sodium Metabolism
}

\author{
A Review with Clinical Implications \\ R. A. DeFronzo \\ Department of Medicine, Divisions of Endocrine-Metabolism and Nephrology, Yale University School of Medicine, \\ New Haven, Connecticut, USA
}

\begin{abstract}
Summary. Data are discussed which demonstrate that insulin plays an important role in sodium metabolism. The primary action of insulin on sodium balance is exerted on the kidney. Increases in plasma insulin concentration within the physiological range stimulate sodium reabsorption by the distal nephron segments and this effect is independent of changes in circulating metabolites or other hormones. Several clinical situations are reviewed: sodium wasting in poorly controlled diabetics, natriuresis of starvation, anti-natriuresis of refeeding and hypertension of obesity, in which insulin-mediated changes in sodium balance have been shown to play an important pathophysiological role.
\end{abstract}

Key words: Insulin, sodium, kidney, diabetes, obesity, hypertension

Over the last ten years a large body of information has accumulated which indicates that physiological changes in the plasma insulin concentration are capable of affecting electrolyte transport by the kidney as well as by a variety of other tissues. In the present discussion the effect of insulin on the renal handling of sodium will be reviewed and an attempt will be made to relate the effects of insulin on sodium metabolism to different clinical situations.

\section{Insulin and Sodium}

The studies of Atchley et al. [1] were the first to suggest that insulin could affect renal sodium handling. Following the abrupt withdrawal of insulin therapy in patients with diabetes mellitus, they demonstrated a marked increase in sodium excretion which appeared to be in excess of the observed gly- cosuria and occurred before the development of ketonuria. Reinstitution of insulin therapy resulted in a marked reduction in sodium excretion, again unrelated to changes in glycosuria or ketonuria. However, changes in the filtered load of glucose and sodium, extracellular fluid volume, glomerular filtration rate (GFR) and renal plasma flow (RPF), as well as possible changes in aldosterone secretion due to changes in fluid volume, may have conspired to alter sodium excretion in these patients. In a more adequately controlled study, Miller and Bogdonoff [2] observed a reduction in urinary sodium excretion after insulin administration to normal subjects undergoing either a solute (glucose) diuresis or a water diuresis. Studies carried out on fasted obese subjects also suggested an effect of insulin on renal sodium transport [3-5]. After prolonged fasting, refeeding with carbohydrate, which results in both hyperinsulinaemia and hyperglycaemia, leads to marked retention of sodium by the kidney. However, these studies do not differentiate between an effect of hyperglycaemia versus hyperinsulinaemia on renal electrolyte transport. The ability of insulin in vitro to increase the short circuit current (a measure of sodium transport) across amphibian epithelia [6-10] suggested that it was the hyperinsulinaemia per se and not the hyperglycaemia that was responsible for the stimulation of sodium transport in the previously discussed clinical situations. It should be noted that the toad bladder and other amphibian epithelia possess electrolyte transporting characteristics similar to the mammalian distal tubule.

\section{Hyperglycaemia, Hyperinsulinaemia, and Sodium Transport by the Kidney}

To examine the differential effects of hyperglycaemia versus hyperinsulinaemia on whole kidney and seg- 


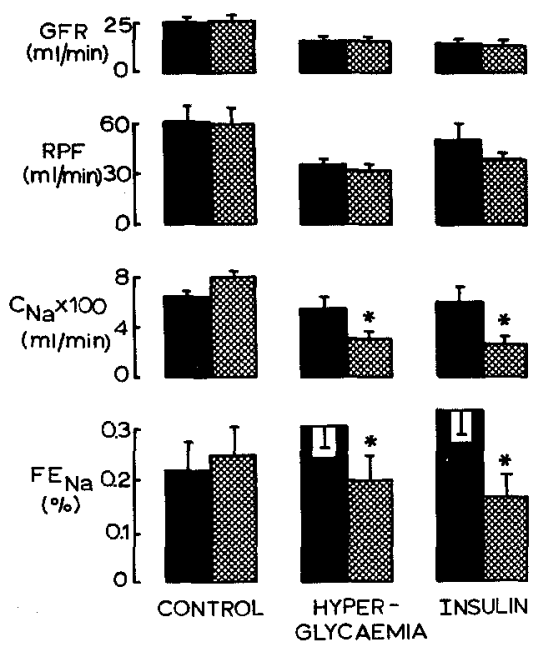

Fig. 1. Glomerular filtration rate (GFR), renal plasma flow (RPF), sodium clearance $\left(\mathrm{C}_{\mathrm{Na}}\right)$, and the fractional excretion of sodium $\left(\mathrm{FE}_{\mathrm{Na}}\right)$ in dogs pre- and post-infusion of sodium chloride (control), glucose clamp (hyperglycaemia) and euglycaemic insulin clamp (insulin). $\mathbf{\square}=$ pre-infusion; $=$ post-infusion. * denotes statistical significance of difference between pre- and post-infusion values $(p<0.02)$. (From DeFronzo et al. [11])

mental renal sodium transport [11], we have employed the glucose clamp technique [12] in combination with recollection micropuncture techniques. Three groups of dogs were studied (Fig. 1). In all three groups baseline (pre) whole kidney clearance and micropuncture collections were carried out over a 60-90 min period. Dogs then received either: 1) maintenance infusion (control study), 2) hyperglycaemic clamp to create a state of combined hyperglycaemia and hyperinsulinaemia (hyperglycaemia); or 3) insulin clamp to create a state of euglycaemic hyperinsulinaemia (insulin). During the control study, the baseline (pre) plasma glucose (5.2 \pm $0.2 \mathrm{mmol} / \mathrm{l})$ and insulin $(57 \pm 14 \mathrm{nmol} / \mathrm{l}$ or $8 \pm$ $2 \mathrm{mU} / \mathrm{l}$ ) levels remained unchanged as a function of time (post). In the hyperglycaemia study the plasma glucose concentration was acutely raised and maintained at $8.9 \pm 0.2 \mathrm{mmol} / 1$ by a prime-variable glucose infusion. The baseline insulin concentration ( 43 $\pm 7 \mathrm{nmol} / 1$ or $6 \pm 1 \mathrm{mU} / \mathrm{l}$ ), increased to a mean of $266 \pm 107 \mathrm{nmol} / \mathrm{l}$ (or $37 \pm 15 \mathrm{mU} / 1$ ) under these steady-state conditions of hyperglycaemia. In the insulin study, a prime-continuous insulin infusion was given to raise and maintain the plasma insulin concentration at $517 \pm 57 \mathrm{nmol} / 1$ (or $72 \pm 8 \mathrm{mU} / 1$ ), while the plasma glucose concentration was held constant at the basal level with a variable glucose infusion. It should be emphasised that the plasma insulin levels achieved during both the hyperglycaemic and insulin clamp studies are well within the physiological range. In fact, in many insulin-resistant states, such as
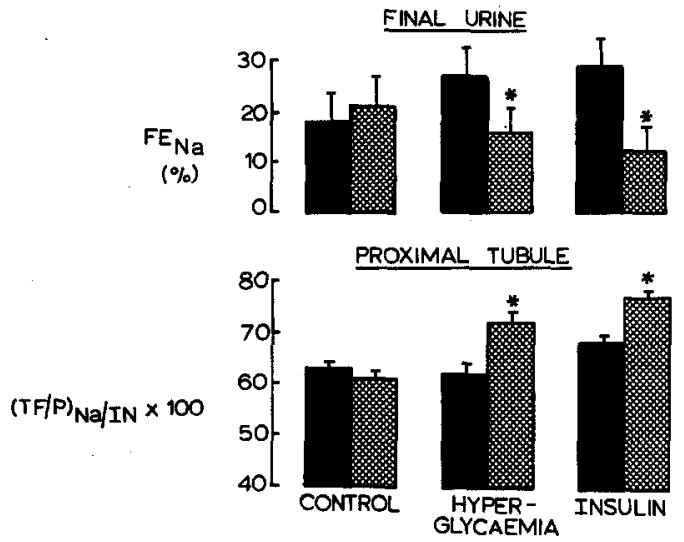

Fig. 2. Changes in whole kidney fractional excretion of sodium $\left(\mathrm{FE}_{\mathrm{Na}}\right)$ and the fractional delivery of sodium $\left([\mathrm{TF} / \mathrm{P}]_{\mathrm{Na} / \mathrm{NN}}\right)$ to the proximal tubule of dogs pre- and post-infusion of sodium chloride (control), glucose clamp (hyperglycaemia) and euglycaemic insulin clamp (insulin). $\mathbf{\square}=$ pre-infusion; $=$ post-infusion. ${ }^{*}$ denotes statistical significance of difference between pre- and post-infusion values $(p<0.02)$. (From DeFronzo et al. [11])

obesity, the fasting insulin levels are not dissimilar from those observed in the above clamp studies.

In the control experiment (Fig. 1), there were no changes in GFR, RPF, absolute sodium excretion $\left(\mathrm{U}_{\mathrm{Na}} \mathrm{V}\right)$, sodium clearance $\left(\mathrm{C}_{\mathrm{Na}}=\frac{\mathrm{U}_{\mathrm{Na}} \mathrm{V}}{\mathrm{P}_{\mathrm{Na}}}\right)$, or the fractional excretion of sodium $\left(\mathrm{FE}_{\mathrm{Na}}=\frac{\mathrm{C}_{\mathrm{Na}}}{\mathrm{GFR}}\right)$. With hyperglycaemic hyperinsulinaemia $\mathrm{U}_{\mathrm{Na}} \mathrm{V}, \mathrm{C}_{\mathrm{Na}}$, and $\mathrm{FE}_{\mathrm{Na}}$ all fell by approximately $35 \%$ without any change in GFR or RPF. The results of the euglycaemic insulin clamp (Fig. 1, third column) demonstrate that it is hyperinsulinaemia per se, and not hyperglycaemia, which is responsible for the sodium retentive effects. Despite unchanged plasma glucose levels, insulin resulted in a greater than $50 \%$ decline in renal sodium excretion. This study, however, does not differentiate between a direct effect of insulin on sodium transport and one secondary to a stimulation of insulin-mediated glucose metabolism.

\section{Tubular Localization of Insulin Action}

In order to delineate the renal tubular segments involved in sodium transport, we have [11] inserted micropipettes into the proximal tubule to collect tubular fluid samples pre and post alteration of the plasma glucose and insulin levels (Fig. 2). As can be seen in the first column (bottom panel), there was no 


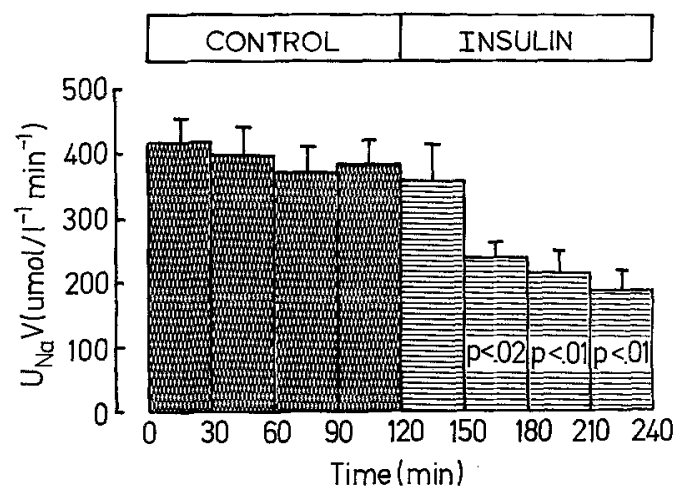

Fig. 3. The time course of decrease in sodium excretion $\left(U_{\mathrm{Na}} \mathrm{V}\right)$ in man following insulin infusion while maintaining euglycaemia. Data represent mean values + SEM of six subjects. 局 $=$ insulin (From DeFronzo et al. [13])

change in the fractional delivery $(\mathrm{TF} / \mathrm{P})_{\mathrm{Na} / \mathrm{IN}}$ of sodium to the proximal convoluted tubule as a function of time. In contrast, both hyperglycaemic hyperinsulinaemia (second column) and euglycaemic hyperinsulinaemia led to enhanced delivery of sodium out of the proximal tubule, i. e. inhibited proximal tubular reabsorption. Nonetheless, whole kidney sodium excretion fell by $35-50 \%$ (Fig. 2, top panel). These results indicate that the effect of insulin on sodium reabsorption must occur in more distal parts of the nephron, i. e. par recta of the proximal tubule, loop of Henle, distal convoluted tubule, collecting duct. The localization of the anti-natriuretic effect of insulin to portions of the nephron distal to the site of proximal puncture in the above micropuncture studies is in agreement with free water clearance studies which suggest that the effect of insulin on sodium transport occurs in the distal convoluted tubule or the thick ascending limb of Henle $[13,14]$. To define the precise tubular segment(s) involved, further studies employing combined distal and proximal micropuncture will be necessary.

\section{Primary Versus Secondary Effect of Insulin on the Kidney}

Two groups have attempted to define whether insulin exerts a direct effect on the kidney or whether its action is secondary to alterations in the hormonal or metabolic milieu to which the kidney is exposed [11, 15]. We have infused insulin directly into the left renal artery at a rate calculated to raise the local plasma insulin concentration by $215-287 \mathrm{nmol} / 1$ (or $30-40 \mathrm{mU} / \mathrm{l}$ ) without significantly changing the systemic insulin concentration [11]. This resulted in a $50 \%$ decline in sodium excretion by the insulin perfused kidney without any change in sodium excretion by the contralateral kidney. Evidence for a direct effect of insulin on renal sodium handling has also been provided by Nizet et al. [15]. Using the isolated perfused kidney they observed that addition of insulin to the perfusing medium led to a prompt reduction in sodium excretion independent of changes in GFR and RPF. It would, thus, appear that the effect of insulin on the kidney is a direct one.

\section{Insulin and Sodium Excretion in Man}

The studies summarised above clearly demonstrate that physiological changes in the plasma insulin concentration are capable of affecting sodium transport in animals both in vivo and in vitro. Two groups have subsequently shown that insulin has similar antinatriuretic effect in man [2,13]. Miller and Bogdonoff [2] were the first to demonstrate clearly that insulin administration in man could lead to a reduction in sodium excretion independent of changes in plasma glucose concentration. The time course of this effect was subsequently studied by our own group [13]. Following four 30-min control urine collections, euglycaemic hyperinsulinaemia (steady-state plasma insulin concentration $=1070 \pm 108 \mathrm{nmol} / 1$ or $(149$ $\pm 15 \mathrm{mU} / \mathrm{l}$ ) was created employing the insulin clamp technique (Fig. 3). Within $30 \mathrm{~min}$ of initiating the insulin infusion, a slight decrease in $\mathrm{U}_{\mathrm{Na}} \mathrm{V}(p=0.10)$ was observed and within $60 \mathrm{~min}$ a highly significant reduction was documented. Over the subsequent hour $\mathrm{U}_{\mathrm{Na}} \mathrm{V}$ continued to decline, reaching a value $50 \%$ less than that during the control period. This anti-natriuretic effect of insulin was observed in the absence of changes in the filtered load of glucose, GFR, RPF, and plasma aldosterone concentration.

\section{Insulin and Sodium: Clinical Implications}

\section{Diabetes Mellitus}

It is commonly stated that sodium wasting in poorly controlled diabetics results from glycosuria and the resultant osmotic diuresis. If significant ketonuria is present this may also contribute to the natriuresis since the negatively charged ketone body necessitates the excretion of an equivalent number of positively charged ions (primarily $\mathrm{Na}^{+}, \mathrm{K}^{+}, \mathrm{NH}_{4}^{+}$) to maintain electrical neutrality. A less well recognised factor, which may contribute to the excessive sodium wasting, is insulin lack per se. The data summarised in the first half of this review have clearly documented that physiological increases in the plasma insulin concentration induce sodium retention. Conversely, recent studies have shown that infusion of somatostatin, a 
potent inhibitor of insulin secretion, causes an increase in urinary sodium excretion [16]. Within the first hour following somatostatin infusion, plasma insulin levels declined by $45 \%$ from 144 to $79 \mathrm{nmol} / 1$ (or 20-11 mU/1). This was associated with a small, transient decline in urinary sodium excretion. Thereafter, a sustained increase in $\mathrm{U}_{\mathrm{Na}} \mathrm{V}$ ensued which persisted throughout the 4-h duration of study.

In order to assess the contribution of insulin lack, Saudek et al. [17] studied six poorly controlled diabetics, only one of whom had significant ketonuria. At the time of admission sodium excretion was excessive. With the institution of insulin therapy, $\mathrm{U}_{\mathrm{Na}} \mathrm{V}$ fell markedly and was well below the dietary intake. This initial decline in $\mathrm{U}_{\mathrm{Na}} \mathrm{V}$ did not correlate with either the fall in plasma glucose concentration or the decline in urinary glucose excretion. However, the possibility that pre-existing sodium deficits were reponsible for the decline in $\mathrm{U}_{\mathrm{Na}} \mathrm{V}$ now that the filtered glucose load had diminished could not be excluded. To examine this subjects were placed on a high sodium intake for 2 weeks and their daily insulin replacement was continued. On day 14 , when insulin was discontinued, an abrupt increase in $\mathrm{U}_{\mathrm{Na}} \mathrm{V}$ was observed. To avoid negative sodium balance the dietary sodium intake was increased to exceed urinary sodium losses. When insulin therapy was reinstituted on day 16 , a marked decline in $\mathrm{U}_{\mathrm{Na}} \mathrm{V}$ again occurred. Changes in glucose excretion were small and did not correlate with changes in $\mathrm{U}_{\mathrm{Na}} \mathrm{V}$. These results indicate that insulin lack per se, independent of glycosuria and ketonuria, contributes to the sodium wasting in poorly controlled diabetics.

\section{Fasting and Refeeding}

It is well known that following total starvation excessive renal sodium losses occur and that following refeeding marked sodium retention results [5, 18-28]. Several mechanisms have been put forward to account for these changes. During starvation significant changes in the hormonal and metabolic milieu in which the kidney is bathed occur $[29,30]$. Plasma insulin levels decline and glucagon increases; ketonaemia, ketonuria, and metabolic acidosis develop and there are alterations in the activity of the sympathetic nervous system [31]. Changes in aldosterone secretion and sensitivity have also been postulated [32-35].

Kolanowski et al. have carried out the most extensive studies on the natriuresis of fasting and the anti-natriuresis associated with refeeding [5, 18-20]. They found that when obese subjects were placed on a constant, moderately restricted sodium intake containing no calories, $\mathrm{U}_{\mathrm{Na}} \mathrm{V}$ increased to exceed intake by approximately $30-40 \mathrm{mmol}$ of sodium/day for the first 3 days and then started to decline. However, even by day 7 of fasting, sodium excretion significantly exceeded sodium intake. If the same subjects were refed with oral or IV glucose on day 4 of fasting, a prompt and sustained reduction in $\mathrm{U}_{\mathrm{Na}} \mathrm{V}$ ensued and all subjects went into positive sodium balance. These basic observations have been repeated by numerous investigators, using slightly different experimental designs [21-28; review by Weinsier 23].

Several hormonal factors have been implicated in the alterations in renal sodium handling following starvation and refeeding. During starvation glucagon levels rise and the time course of rise parallels the increase in $\mathrm{U}_{\mathrm{Na}} \mathrm{V}$. The converse occurs during refeeding. Since pharmacological doses of glucagon have been shown to increase sodium excretion [38], it has been suggested that glucagon is the hormone responsible for the changes in sodium excretion following starvation and refeeding [32, 36, 37]. Recent studies by Kolanowksi, however, have made this hypothesis untenable [19]. If glucagon is administered with glucose on day 4 of starvation, the antinatriuresis of glucose persists. Other studies also suggest that changes in plasma glucagon levels within the physiological range have little effect on renal sodium handling $[19,38]$. Changes in aldosterone secretion and/or sensitivity have also been suggested to play an important role in the altered sodium metabolism following caloric deprivation and refeeding [32-35]. However, during the first 3 days of starvation, plasma aldosterone levels increase while sodium excretion also rise [18, 35, 39]. Furthermore, Kolanowski has demonstrated normal tubular responsiveness to aldosterone during this period of caloric deprivation [18]. In addition, spironolactone failed to block the natriuresis of fasting or the anti-natriuresis following refeeding [40]. Most recently, Landsberg and Young have demonstrated decreased sympathetic nervous system activity following starvation which is reversed following refeeding [31]. Since increased circulating catecholamines and stimulation of the renal sympathetic nerves are capable of enhancing sodium reabsorption by the kidney $[41,42]$, it is possible that the natriuresis of starvation and its reversal following feeding are related to changes in circulating catecholamine levels or sympathetic nervous system activity. Further studies will be needed to clarify this potentially important relationship.

The last and most probable hormone responsible for the alterations in sodium balance following starvation and refeeding is insulin. Caloric deprivation is associated with a prompt decline in circulating insulin levels and carbohydrate refeeding is associated with a 
stimulation of insulin secretion [29]. Previous studies by our group have shown that inhibition of basal insulin secretion is followed by a natriuresis [16] and elevation of the plasma insulin concentration by as little as $215 \mathrm{nmol} / 1$ (or $30 \mathrm{mU} / \mathrm{l}$ ) is associated with an anti-natriuresis [11]. The changes in plasma insulin levels that occur in starvation and refeeding are well within the range reported by DeFronzo et al $[11,16]$ as affecting renal sodium excretion. It must be emphasised that hypoinsulinaemia is associated with two other important metabolic changes: metabolic acidosis and ketonuria.

Previous studies have shown that both acute [43] and chronic [44] metabolic acidosis inhibit sodium reabsorption by the kidney. Studies by Stinebaugh and Schloeder [27] suggest that as much as one-third of the ensuing natriuresis following starvation may be due to the development of systemic acidosis. The inability of sodium bicarbonate administration to prevent the natriuresis $[18,45]$ does not exclude a role for metabolic acidosis since the blood $\mathrm{pH}$ was not measured in these studies. A better established factor contributing to the natriuresis of fasting is the development of ketonuria. During the first 3 days of fasting, the increase in sodium excretion closely parallels the increase in ketone excretion [20, 22]. During this time ammonium excretion increases little. Starting on day 4 of fasting ammonium excretion begins to increase markedly and ammonium replaces sodium as the predominant positively charged ion in the urine. If the fast is interrupted by glucose feeding, the decline in $\mathrm{U}_{\mathrm{Na}} \mathrm{V}$ closely parallels the decline in ketone excretion. On the other hand, changes in ketone excretion cannot be the only factor reponsible for the changes in sodium metabolism following fasting and refeeding since protein feeding can similarly reduce sodium excretion despite persistent ketonuria. In summary, it would appear that insulin lack per se, ketonuria and perhaps metabolic acidosis all play important roles in the natriuresis of fasting and subsequent anti-natriuresis that follows refeeding.

\section{Obesity and Hypertension}

Much information has been accumulated that documents a markedly increased incidence of hypertension in obese individuals [46-49]. Despite the fact that hypertension is a well-established risk factor for the development of coronary artery disease, little is known about the specific factors which are responsible for the high prevalence of high blood pressure in overweight individuals.

Blood pressure is primarily determined by two factors: cardiac output and the peripheral vascular resistance. Both of these are dependent on the total body sodium content and neurohormonal factors. Little is known about the contribution of the sympathetic nervous system and the renin-angiotensinaldosterone system to the hypertension observed in obesity. Several recent studies have suggested that hyperinsulinaemia, perhaps acting by enhanced renal sodium absorption, plays a causative role in the hypertension. Dahl et al. [50] examined the ability of three regimens: a) salt restriction; b) caloric restriction, and c) combined salt and caloric restriction to normalize the blood pressure in obese, hypertensive individuals. Salt restriction alone and combined saltcaloric restriction resulted in a near normalization of blood pressure, whereas caloric restriction while maintaining sodium balance was without effect. These results would suggest that it is sodium, not weight loss, which is associated with the reduction in blood pressure. It shuld be noted that this important study involved small numbers of patients (four to five) in each group and has yet to be repeated. Reisin et al. [51] have reached a different conclusion. They treated obese hypertensive subjects with a hypocaloric, normal salt diet and found a highly significant reduction in blood pressure. These authors concluded that it was the weight reduction per se that was responsible for the reduction in blood pressure. However, no measurements of sodium balance were made during the period of weight loss, and the maintenance of a normal dietary sodium intake does not exclude a significant negative sodium balance. Several other studies $[47,48,52,53]$ have also reported reductions in blood pressure following weight reduction, but no attempt was made to assess sodium balance in any of these studies.

One factor that is common to all of these studies involving weight reduction is that the plasma insulin concentration fell significantly. It is well known that obesity is a state of insulin resistance and is characterized by fasting hyperinsulinaemia and excessive insulin secretion to glucose stimulation [54]. Fasting insulin levels in the $215-359 \mathrm{nmol} / 1(30-50 \mathrm{mU} / \mathrm{l})$ range are not uncommon in obese individuals. Following caloric restriction and weight loss, there is a marked reduction in fasting and glucose-stimulated insulin levels $[55,56]$. How might these changes in plasma insulin concentration be related to the improvement in blood pressure control? As discussed earlier, an increase in plasma insulin concentration of only $215 \mathrm{nmol} / 1(30 \mathrm{mU} / \mathrm{l})$ can result in significant sodium retention. Thus, it is possible that the insulin resistance with respect to glucose metabolism leads to hyperinsulinaemia, which subsequently stimulates sodium reabsorption by the kidney and expands the extracellular fluid volume (Fig. 4). As demonstrated 


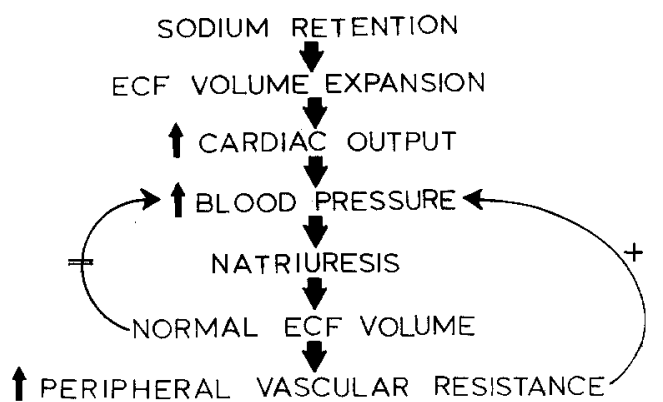

Fig. 4. Pathogenesis of hypertension following excessive sodium retention and expansion of the extracellular fluid (ECF) volume

by Guyton et al. [57] and reviewed by Tobian [58] and Freis [59], continued expansion of the extracellular fluid volume by salt and water will lead to an increase in cardiac output and rise in blood pressure (Fig. 4). As the perfusion pressure to which the kidney is exposed increases, eventually the anti-natriuretic effect of insulin will be overcome and a natriuresis will ensue (Fig. 4). However, as the extracellular fluid returns toward normal, blood pressure will tend to fall, sodium reabsorption will be stimulated, and the cycle will repeat itself. In some as yet unknown fashion, the body perceives the need to maintain an elevated blood pressure to prevent the excessive sodium retention that would otherwise occur with hyperinsulinaemia. There follows an increase in the peripheral vascular resistance which is then responsible for the sustained elevation in blood pressure. Insulin may also affect the peripheral vascular resistance directly by influencing sodium and/or calcium uptake by the arterial smooth muscle [60].

When obese subjects are treated with a hypocaloric diet, plasma insulin levels fall [5, 18-20, $29,30,55,56]$; this is associated with marked negative sodium balance $[5,18-28]$ and an improvement in blood pressure control $[47,50,53,54,58]$. These observations suggest that insulin, working through sodium, plays an important contributory role in the hypertension so commonly observed in obese subjects. The lack of improvement in blood pressure control following weight reduction when negative sodium balance was prevented from occurring offers support for this contention [50]. These observations stress the importance of weight reduction and amelioration of hyperinsulinaemia in the treatment of hypertension in the obese.

\section{References}

1. Atchley DW, Loeb RF, Richards DW, Benedict EM, Driscoll ME (1933) On diabetic acidosis. J Clin Invest 12: 297-326

2. Miller JH, Bogdonoff MD (1954) Antidiuresis associated with administration of insulin. J Appl Physiol 6: 509-512
3. Veverbrants E, Arky RA (1969) Effects of fasting and refeeding. I. Studies on sodium, potassium, and water excretion on a constant electrolyte and fluid intake. J Clin Endocrinol Metab 29: $55-62$

4. Hoffman RS, Martino JA, Wahl G, Arky RA (1960) Effects of fasting and refeeding. II. Tubular sites of sodium reabsorption and effects of oral carbohydrate on potassium, calcium, and phosphate excretion. J Lab Clin Med 74: 915-926

5. Kolanowski J, deGasparo M, Desmecht P, Crabbe J (1972) Further evaluation of the role of insulin in sodium retention associated with carbohydrate administration after a fast in the obese. Eur J Clin Invest 2: 439-444

6. Herrera FC, Whittembury G, Planchard A (1963) Effect of insulin on short-circuit current across isolated frog skin in the presence of calcium and magnesium. Biochim Biophys Acta 66: $170-172$

7. Andre R, Crabbe J (1966) Stimulation by insulin of active sodium transport by toadskin: influence of aldosterone and vasopressin. Arch Int Physiol Biochim 74: 538-540

8. Crabbe J, Francois B (1967) Stimulation par l'insuline du transport actif de sodium à travers des membranes epitheliales du crapaud, Bufo marinus. Ann Endocrinol 28: 713-715

9. Francois B, deGasparo M, Crabbe J (1969) Interaction between isolated amphibian skin and insulin. Arch Int Physiol Biochim 77: 527-530

10. Herrera FC (1965) Effect of insulin on short-circuit current and sodium transport across toad urinary bladder. Am J Physiol 209: 819-824

11. DeFronzo RA, Goldberg M, Agus Z (1976) The effects of glucose and insulin on renal electrolyte transport. J Clin Invest 58: $83-90$

12. DeFronzo RA, Tobin J, Andres R (1979) The glucose clamp technique. A method for the quantification of beta cell sensitivity to glucose and of tissue sensitivity to insulin. Am J Physiol 237: E214-E223

13. DeFronzo RA, Cooke CR, Andres R, Faloona GR, Davis PJ (1975) The effect of insulin on renal handling of sodium, potassium, calcium, and phosphate in man. J Clin Invest 55: 845-855

14. Schloeder FX, Stinebaugh BJ (1970) Renal tubular sites of natriuresis of fasting and glucose-induced sodium conservation. Metab (Clin Exp) 19: 1119-1128

15. Nizet A, Lefebvre P, Crabbe J (1971) Control by insulin of sodium, potassium, and water excretion by the isolated dog kidney. Pfluegers Arch Eur J Physiol 323: 11-20

16. DeFronzo RA, Sherwin RS, Dillingham M, Hendler R, Tamborlane WT, Felig P (1978) Influence of basal insulin and glucagon secretion on potassium and sodium metabolism. $\mathbf{J}$ Clin Invest 61: 472-479

17. Saudek CD, Boulter PR, Knopp RH, Arky RA (1974) Sodium retention accompanying insulin treatment of diabetes mellitus. Diabetes 23: 240-246

18. Kolanowski J, Pizaro MA, deGasparo M, Desmecht P, Harvengt $C$, Crabbe J (1970) Influence of fasting on adrenocortical and pancreatic islet response to glucose loads in the obese. Eur J Clin Invest 1: 25-31

19. Kolanowski J, Salvador G, Desmecht P, Henquin JC, Crabbe J (1977) Influence of glucagon on natriuresis and glucoseinduced sodium retention in the fasting obese subject. Eur $\mathbf{J}$ Clin Invest 7: 167-175

20. Kolanowski J, Bodson A, Desmecht P, Bemelmans S, Stein F, Crabbe J (1978) On the relationship between ketonuria and natriuresis during fasting and upon refeeding in obese patients. Eur J Clin Invest 8: 277-282

21. Boulter PR, Hoffman RS, Arky RA (1973) Pattern of sodium excretion accompanying starvation. Metabolism 22: 675682 
22. Sigler MH (1975) The mechanism of the natriuresis of fasting. J Clin Invest 55: 377-387

23. Weinsier RL (1971) Fasting - a review with emphasis on the electrolytes. Am J Med 50: 233-240

24. Bloom WL, Mitchell W Jr (1960) Salt excretion of fasting patients. Arch Intern Med 106: 321-327

25. Stinebaugh FJ, Schloeder FX (1966) Studies on the natriuresis of fasting. I. Effect of pre-fast intake. Metabolism 15: 828-837

26. Schloeder FX, Stinebaugh BJ (1965) Electrolyte excretion in subjects fasting in tropical environment. Arch Intern Med 116: 866-870

27. Stinebaugh BJ, Schloeder FX (1966) Studies on the natriuresis of fasting. II. Relationship to acidosis. Metabolism 15: 838-846

28. Hoffman RS, Martino JA, Wahl G, Arky RA (1971) Fasting and refeeding. III. Antinatriuretic effect of oral and intravenous carbohydrate and its relationship to potassium excretion. Metabolism 20: 1065-1073

29. Cahill CF (1970) Starvation in man. N Engl J Med 282: 668-675

30. Cahill GF Jr. Owen OE, Morgan AP (1968) The consumption of fuels during prolonged starvation. Adv Enzyme Reg 6: $143-150$

31. Landsberg L, Young JB (1978) Fasting, feeding, and regulation of the sympathetic nervous system. N Engl J Med 298: 1295-1301

32. Spark RF, Arky RA, Boulter PB, Saudek CD, O'Brian JJ (1975) Renin, aldosterone, and glucagon in the natriuresis of fasting. N Engl J Med 292: 1335-1340

33. Boulter PR, Spark RF, Arky RA (1973) Effect of aldosterone blockade during fasting and refeeding. Am $J$ Clin Nutr 26: 397-402

34. Verdy M, deChamplain J (1968) Fasting in obese females: II. Plasma renin activity and urinary aldosterone. Can Med Assoc J 98: 1034-1037

35. Garnett ES, Cohen H, Nahmias C, Viol G (1973) The roles of carbohydrate, renin, and aldosterone in sodium retention during and after total starvation. Metabolism 22: 867-874

36. O’Brian J, Saudek CD, Spark RF, Arky RA (1974) Glucagoninduced refractoriness to exogenous mineralocorticoid. J Clin Endocrinol Metab 28: 1147-1149

37. Saudek CD, Boulter PR, Arky RA (1973) The natriuretic effect of glucagon. Its role in starvation. $\mathrm{J}$ Clin Endocrinol Metab 36: 761-765

38. Levy M, Starr NL (1972) The mechanism of glucagon-induced natriuresis in dogs. Kidney Int 2: 76-84

39. Chinn RH, Brown JJ, Fraser R, Heron SM, Lever AF, Murchison L, Robertson JIS (1970) The natriuresis of fasting: relationship to changes in plasma renin and aldosterone concentrations. Clin Sci 39: 437-455

50. Gersing A, Bloom WL (1962) Glucose stimulation of salt retention in patients with aldosterone inhibition. Metabolism 11: $329-336$

41. Bello-Reuss E, Colindres RE, Pastoriza-Munoz E, Mueller RA, Gottschalk CW (1975) Effect of acute unilateral renal denervation in the rat. J Clin Invest 56: 208-217

42. Besarob A, Silva P, Lansberg L, Epstein F (1977) Effect of catecholamines on tubular function in the isolated perfused rat kidney. Am J Physiol 233: F39-F45

43. Mahnensmith R, Thier SO, Cooke CR, Broadus A, DeFronzo RA (1979) Effect of acute metabolic acidemia on renal electrolyte transport in man. Metabolism 28: 831-842
44. Lemann J Jr., Litzow JR, Lennon EJ (1967) Studies of the mechanism by which chronic metabolic acidosis augments calcium excretion in man. $\mathrm{J}$ Clin Invest 46: 1318-1328

45. Veverbrants E, Arky RA (1969) Effects of fasting and refeeding. I. Studies on sodium, potassium, and water excretion on a constant electrolyte and fluid intake. J Clin Endocrinol 29: $55-62$

46. Alexander J, Dustan HP, Sims EAH, Tarazi RC (1979) Obesity. In: Report of the hypertension task force. NIH Publication $79-1623$

47. Chiang BN, Perlman LV, Epstein FH (1969) Overweight and hypertension. Circulation 39: 403-421

48. Tyroler HA, Heyden S, Hames CG (1975) Weight and hypertension: Evans County studies of blacks and whites. In: Paul O (ed) Epidemilogy and control of hypertension. Stratton International, New York, pp 177-201

49. Kannel WB, Brand N, Skinner JJ (1967) The relation of adiposity to blood pressure and development of hypertension: the Framingham study. Ann Intern Med 67: 48-59

50. Dahl LK, Silver L, Christie RW (1958) The role of salt in the fall of blood pressure accompanying reduction in obesity. $\mathrm{N}$ Engl J Med 258: 1186-1192

51. Reisin E, Abel R, Modan M, Silverberg DS, Eliahou HE, Modan B (1978) Effect of weight loss without salt restriction on the reduction of blood pressure in overweight hypertensive patients. N Engl J Med 298: 1-6

52. Martin L (1952) Effect of weight reduction on normal and raised blood pressures in obesity. Lancet 2: 1051-1053

53. Fletcher AP (1954) The effect of weight reduction upon the blood pressure of obese hypertensive women. Q J Med 23: 331-345

54. DeFronzo RA, Soman V, Sherwin RS, Hendler R, Felig P (1978) Insulin binding to monocytes and insulin action in human obesity, starvation, and refeeding. J Clin Invest 62: 204-213

55. Sims EAH, Danforth E, Horton ES, Bray GA, Glennon JA, Salans LB (1973) Endocrine and metabolic effects of experimental obesity in man. Rec Prog Hormone Res 29: 457-487

56. Stanik S, Marcus R (1980) Insulin secretion improves following dietary control of plasma glucose in hyperglycemic obese patients. Metabolism 29: 346-350

57. Guyton ACJ, Coleman TG, Cawley AW, Manning RD, Norman RA, Ferguson JD (1974) A systems analysis approach to understanding long range arterial blood pressure control and hypertension. Circ Res 35: 159-176

58. Tobian L (1972) A viewpoint concerning the enigma of hypertension. Am J Med 52: 595-609

59. Freis ED (1976) Salt, volume, and prevention of hypertension Circulation 53: 589-595

60. Birkenhauger WH, deLeeuw PW (1979) Pathophysiological mechanisms in essential hypertension. Pharmacol Ther 8: 297-319

Ralph A. DeFronzo

Department of Medicine

Divisions of Endocrine Metabolism and Nephrology

Yale University School of Medicine

New Haven

CT 06510, USA 